This item was submitted to Loughborough's Research Repository by the author.

Items in Figshare are protected by copyright, with all rights reserved, unless otherwise indicated.

\title{
Spiritualism exposed: scepticism, credulity and spectatorship in end-of-the- century America
}

\section{PLEASE CITE THE PUBLISHED VERSION}

http://dx.doi.org/10.1386/ejac.29.2.131_1

\section{PUBLISHER}

(C) Intellect Ltd

\section{VERSION}

AM (Accepted Manuscript)

\section{PUBLISHER STATEMENT}

This work is made available according to the conditions of the Creative Commons Attribution-NonCommercialNoDerivatives 4.0 International (CC BY-NC-ND 4.0) licence. Full details of this licence are available at: https://creativecommons.org/licenses/by-nc-nd/4.0/

\section{LICENCE}

CC BY-NC-ND 4.0

\section{REPOSITORY RECORD}

Natale, Simone. 2019. "Spiritualism Exposed: Scepticism, Credulity and Spectatorship in End-of-the-century America”. figshare. https://hdl.handle.net/2134/19411. 


\title{
Spiritualism exposed: Scepticism, credulity and spectatorship in end-of-the-century
}

\section{America}

Simone Natale, University of Turin

Published in: European Journal of American Culture 29.2 (2010): 131-144

\begin{abstract}
In recent years, the study of spiritualism and occultism has been proposed as a key to understand the political, social and cultural issues of nineteenth-century America. While the position of spiritualism's supporters has been the subject of most accounts, however, sources that critically questioned the spiritualist claims have been usually left aside. In this article, I will rely on this extremely rich body of sources, in order to understand how the debate about spiritualism played an essential role in the shaping of sceptical perspectives in nineteenthcentury America. Focusing in particular on anti-spiritualist performances played on the stage by professional magicians and on psychological writings that questioned the phenomena of the spiritualist seances, I will argue that in both contexts the 'spirit medium' came to be understood as a performer, and the sitters as spectators. As a critical reading of texts such as film theory pioneer Hugo Münsterberg's 1891 'Psychology and Mysticism' may suggest, the exposure of spiritualist trickery shaped a discourse on perception and sensorial delusion that anticipated in many ways later debates on cinematic spectatorship.
\end{abstract}

\section{Introduction}

In the last few decades, the rise and evolution of the spiritualist movement in nineteenthcentury America has been the subject of a growing attention. ${ }^{1}$ However, while the position of spiritualism's supporters has been the subject of most accounts, sources that critically questioned the spiritualist claims have been relatively left aside. In the last half of the 
nineteenth century, in Northern America as well as in Europe, scientists of the calibre of Mendeleev, Carpenter and Faraday, celebrated stage magicians such as Houdini and Harry Kellar and eminent psychologists such as Hugo Münsterberg attended seances, wrote essays, gave conferences, directed scientific commissions in order to unmask and explain what they called the 'spiritualist humbug'. These anti-spiritualist efforts represent an extremely rich corpus of sources, whose significance this article intends to restore.

Significantly, the most relevant exceptions to the tendency of leaving aside the anti-spiritualist discourse came from fields involved in the study of visual culture, such as art and photography history. Both Jennifer Mnookin and Jennifer Tucker have acknowledged how the rise in the 1860s of spirit photography, a spiritualist practice that involved the uncanny appearance of images of dead persons on a photographic plate, resulted in a debate that questioned the value of photography as a juridical evidence and a scientific means (Mnookin 1998; Tucker 2005). Moving from this perspective, Michael Leja linked the raising of doubts around the objective status of photography with a number of deceptive practices that were in use in end-of-the-century America, focusing in particular on trompe l'ceil painting (Leja 2004). As these works contribute to demonstrate, with the growing of popular concerns on trickery and frauds, the capacity to exercise a sceptical perspective became central in turn-ofthe-century American visual culture. The possibility of perceptual delusion involved means that before were widely regarded as objective, like photography itself (Orvell 1989), and intersected with fields such as advertisement, popular press, and show business. As Leja put it, 'the visible world was becoming an enchanted realm where fantasy and reality were difficult to distinguish' (Leja 2004: 4). In this article, the link between anti-spiritualist criticism and these concerns will be underlined, in order to understand how the debate on the 'spirit message' played a role in the shaping of sceptical perspectives in nineteenth-century America. Rather than focusing on photography and the still image, I will stress how anti- 
spiritualist criticisms involved the discussion on the capacity of audiences of spectacular entertainments to distinguish between reality and illusion. Thus, I will argue that the debate around spiritualism anticipated questions that had to be central for the discussion of cinematic spectatorship. After having sketched the main arguments and the rhetorical means used by the opponents of spiritualism in nineteenth-century America, I will particularly focus on two types of spiritualist exposés - as anti-spiritualist exposures were often called during the nineteenth century - on the one side, anti-spiritualist performances played on the stage by professional magicians, and on the other, psychological writings that questioned the phenomena of the spiritualist seances. In both contexts, the spirit medium came to be understood as a performer, and the sitters as spectators, addressing questions of spectatorship and visual competence. Analysing texts such as film theory pioneer Hugo Münsterberg's 'Psychology and Mysticism' (1899a), I will thus stress how the exposure of spiritualist trickery shaped a discourse on perception and sensorial delusion that mirrored in many ways the characterization of spectatorship in contemporary visual entertainment, such as cinema.

\section{'A moral duty': Exposing mediumship in nineteenth-century America}

Following most spiritualist sources, the first discovery of a spirit's attempt to communicate with the living took place in Hydesville, a small town in the state of New York. During the first months of 1848, the Fox family, living in a house that had a reputation of being haunted, was unsettled by the mysterious noises by which the spirit of a dead contacted the two younger daughters, Kate and Margaret Fox, who were just nine and twelve years old at that time. According to this narrative, a kind of founding myth for the spiritualist movement, the Fox sisters are thus the first spiritual mediums of history. Although ghost stories and spirit messages are surely much older than this, during the following decades spiritualism became a widespread and relatively cohesive movement, with a myriad of circles, journals, associations 
and mediums, in the United States and abroad. ${ }^{2}$

The exposure of spiritualist phenomena is as old as spiritualism itself. Popular press and publications reported, discussed and often questioned the reliability of spiritualist claims. As early as 1853 , for instance, a booklet informed their readers about the deceiving character of 'spirit-rappings': 'Nothing is more easy than to deceive completely, by calling the attention of persons present to sounds from a certain position or direction, while in reality the sounds are made elsewhere and in a remote quarter' (Page 1853: 43). The Fox sisters were themselves the object of several exposés, in a story of repeated exposures and counterexposures that culminated in their confession, reported by the New York Herald on 24 September 1888 , that the mysterious spirit raps had been actually produced by a voluntary movement of their feet's joints and toes. Shortly later, Reuben Briggs Davenport published a book titled The Death-Blow to Spiritualism, telling 'the true story of the Fox sisters' with a stated confession of the two mediums, in the hope that 'the world will now form its ultimate conclusion upon this flagrant and audacious system of humbuggery' (1888: 13). His book was reprinted several times, up to the recent years, but his 'definitive' exposure had to be neither the last, nor the most effective one. Shortly after, the Fox sisters returned to spiritualist mediumship, refusing to confirm the authenticity of their confession.

Although the 'spiritualist madness' soon spread to Europe and to other parts of the world, in the nineteenth century it was usually understood as something eminently American. L. S. Forbes Winslow, editor of The Journal of Psychological Medicine and Mental Pathology, informed his readers of the 'religious insanity' that still kept being professed despite 'the many exposures of collusion, self-deception, and imposture in connection with the so-called "spirit-mediums"" (1877: 5), asserting that "America is to blame for the propagation of these spiritualistic views' (p. 7). In fact, explained the British psychologist, 'this form of delusion is very prevalent in America, and the asylum contain many of its 
victims; nearly ten thousand persons having gone insane on the subject are confined in the public asylum of the United States' (p. 6). According to Winslow, the number of spiritualist believers in the United States amounted to a million just five years after spiritualism had been in existence. Although, given spiritualism's lack of recognized leadership and organic protocols, it is quite difficult to estimate the actual number of the spiritualist believers, other sources gave even higher estimates, such as 3 million Americans at least peripherally engaged with the movement by the 1850s and over 11 million by the 1870s (Moore 1972: 481).

The strategies used by spiritualists to reject criticism followed well-established patterns. Quite often, spiritualist supporters responded to the exposure of dishonest mediums claiming that the fact that some of them were tricksters demonstrated neither the fallacy of their doctrine nor the dishonesty of other mediums. Thus, in an 1860 edition of the Spiritual Magazine, an editor was keen to point out that 'an impostor, or a thousand impostors, [...] will not remove a single fact' (cited in Lamont 2004: 899). Another way to question their opponents was to oppose their spiritual approach to the materialism of others. In an address delivered before the National Spiritualist Association in 1895, for instance, a speaker that defined himself as a man of science distinguished the 'material' from the 'psychic' science, arguing that 'accumulated facts in the domain of the spiritual, which cry aloud to heaven for recognition and appreciation, outweigh those of matter', giving birth to what he called 'the everlasting shame of materialistic scientists' (Bacon 1896: 7). Despite the alleged refusal of materialism, however, spiritualists gave the utmost importance to the collecting of empirical and supposedly scientific evidence of spirit communication. The involvement in the spiritualist movement of scientists such as the eminent British chemist William Crookes, who in 1861 had discovered the element thallium, was repeatedly pointed as supporting what was frequently called the 'spiritualist science'. Moreover, the use of photography and of a number of other recording devices, measuring among other things the movements of the table during 
the seance, was frequently underlined in order to demonstrate the objectivity of spirit phenomena. $^{3}$

The importance of maintaining a sceptical perspective was evoked again and again, by the opponents of the movement as well as by the spiritualists themselves. In a somehow paradoxical way, the latter used to understand themselves as sceptics, too. In an article published in The North American Review, a spiritualist recalled in this way the circumstances that brought him to embrace his faith: 'such was my skepticism, however, that months elapsed before accumulating evidence compelled me to confess my full satisfaction' (Newton 1888: 663). Quite often, spiritualists firmly attacked those of them who had been exposed as fraudsters. Daniel Douglas Home, one of the most celebrated spirit mediums, who had been giving seances in Britain and in the United States during the 1860s and 1870s, wrote a book, Lights and Shadows of Spiritualism (1877), that could be reasonably listed among the most relevant anti-spiritualist writings. In reporting a number of cases of trickery, however, Home punctually distanced his authentic mediumship from the trickery of those fraudsters. Others, like the group of intellectuals that gathered around the British Society for Psychical Research (SPR) and its American analogue, rejected the claims of the spiritualists only to concentrate on more 'scientific' phenomena, such as the study of telepathy and clairvoyance. Following this pattern, the 1886 report Phantasms of the Living, arguably the most influential publication of the British SPR, attempted to explain spirit phenomena by evoking a telepathic contact with persons who were still in life, rather than with the spirits of the dead (Gurney et al. 1962).

Among straighter exposures of the spiritualist phenomena made by insiders, a particularly effective one was Revelations of a Spirit Medium, where the anonymous author, presented in the preface as 'a "working" medium for the last twenty years' who 'is not guessing or theorizing in what he has written' (A Medium 1891: 3, emphasis in original), 
went so far as to openly stress the rivality between mediums and stage magicians, who explicitly performed tricks for entertaining purposes: 'the "medium" has no apparatus, or, if he has, it cannot be found, and he gives his "séances" in strange rooms, with but a few minutes of preparation.' This superiority in the art of trickery, the author suggested, made of the spiritual medium a veritable 'artist of his line' (p. 17).

Authors of anti-spiritualist writings regarded themselves as virtuous defenders of the victims of the mediumistic humbug. Thus, an M.E. Darby, exposing phenomena such as clairvoyance, trance-speaking and materializations, intended to make 'a warning and guide to the innocent and over-credulous young men' (1888: 4), who were 'a ready prey for the unscrupulous $[s i c]$ and inhuman professional practitioner of legerdemain, who cruelly, out of the most tender ties, feelings, and emotions of human bosoms, make a harvest and find a ready spoil' (p. 36). Spiritualist mediumship was frequently evoked in relation to fears about financial frauds and swindles. The fact that mediums used to ask money for conducting their seance was emphasized over and over, and explicitly connected with other forms of pecuniary abuse, such as those practised by confidence men. The money was not absent in the symbolism of a spiritualist seance: the phenomena experienced may include the temporary disappearance of a wallet or other objects from a sitter's pocket.

P.T. Barnum, who pioneered some of the entertaining and advertising techniques of modern show business, was himself an author of anti-spiritualist writings. In his 1865 The Humbugs of the World, which was intended to be an exposure of deceptions undertaken in several fields, such as science, literature and medicine, he dedicated a large space to the exposure of spiritual seance. After having explained how spiritualism had artfully started with the Fox family's lucrative humbug, Barnum argued that

An aptitude for deception is all the capital that a person requires in order to 
become a 'spirit-medium'; or, at least, to gain the reputation of being one.

Backing up the pretence to mediumship with a show of something mysterious, is all-sufficient to enlist attention, and insure the making of converts. (1865:

Quite predictably, Barnum focused on the underlying economical reasons that had to be found under the activity of probably every medium, and offered high rewards to the spiritualists who could demonstrate their claims following deception-proof conditions.</UIP>

Among the figures most involved in the exposure of spiritualist phenomena, stage magicians played a particularly relevant role at the end of the century. Under the auspices of French clockmaker Robert-Houdin, the greatest magician of every time according to many popular histories of magic, conjuring had become a popular entertainment practice in the second half of the nineteenth century. Magicians of this kind were technically skilful stage performers, whose sketches included the use of optical illusions, magic lanterns, automata, mechanical effects, electricity and, later, early films (Barnouw 1981; Solomon 2006). Antispiritualist shows, usually advertised as 'spiritualist exposé', were soon inserted in the repertoires of stage magic: John Henry Anderson, who besides Robert-Houdin is considered one of the founders of modern magic, started to expose spiritualist humbugs as early as 1855 . However, this kind of spectacle became particularly important in coincidence of the growing success of two mediums, the Davenport brothers. In fact, Ira Erastus and William Henry Davenport, who toured America from the late 1850s and later moved to Britain, explicitly presented their spirit seance to large audiences as a kind of show. Their performances seem to have exerted a great fascination among stage conjurers. John Nevil Maskelyne, probably the leading stage magician in late-nineteenth-century Britain, started his career with a stage exposure of the Davenport brothers' spirit cabinet. Recalling its first contacts with 
spiritualism, Maskelyne wrote in 1891:

I was able in a few months to reproduce every item of the Davenports' cabinet and dark séance. So closed was the resemblance to the original, that the Spiritualists had no alternative but to claim us as most powerful spirit mediums, who found it more profitable to deny the assistance of spirits. (Weatherly 1891: 190)

Maskelyne's 1876 book Modern Spiritualism explained in detail how the Davenports' seance effects were produced. The condition of darkness was one of the most important features of how he described their seances: all their tricks were kept hidden from the audience, 'either by the cabinet doors being closed, or the gas in the hall turned down. To say the least, this antipathy of "spirits" to the light is extremely unfortunate!' (1876: 66). American magician Harry Kellar was also influenced by the two mediums. He was hired by the Davenports as an assistant in 1868, and acquired much of his illusionist skills during this apprenticeship. After breaking his association with them, he specialized in on-stage exposés of spiritualist seance tricks, which set attendance records in New York, Cincinnati and Chicago (Cook 2001: 199). As cultural historian Simon During (2002: 71) pointed out, 'what was magic show one night could (without technical changes) be presented as a spiritualist séance next night'. </UIP> By the turn of the century, anti-spiritualist performances had become an established genre of magic show. Harry Houdini, the most popular American conjurer of his time, claimed in his 1924 A Magician among the Spirits that he had intended the exposure of spiritualist tricksters as a moral duty (1924: 12). Three years later he donated to the Library of Congress what he described as 'one of the largest libraries in the world on psychic phenomena, Spiritualism, magic, witchcraft, demonology, evil spirits, etc., some of the material going back as far as 1489' (cited in Salamanca 1942: 325). This large collection is 
revealing of how anti-spiritualist activities not only played a part in his shows but were a sort of obsession to him. As vaudeville historian Albert McLean suggested, even Houdini's celebrated escape art may have originated in the Davenports' spiritualist shows (McLean 1965: 157). In fact, the Davenport brothers used to tie themselves at the beginning of the seance, in order to ensure the 'spontaneity' of the phenomena, and Maskelyne's exposure of their tricks already involved some kind of escape show (Maskelyne 1876: 66).

Historians have given different interpretations of the involvement of magicians in antispiritualist exposés. According to During, magicians could establish in this way an implicit link with the supernatural, thus profiting from the nineteenth-century fascination for the occultist world (2002: 71). However, their link with anti-spiritualism has probably also to do with a particular strategy by which magicians, calling attention to the existence of an audience which did not recognize similar tricks as such (the sitters of a spiritualist seance), bound their public in a relation of complicity, opposing the spiritualists to the more sceptical spectators of their own shows. Performing spiritualist exposés, end-of-the-century magicians played with the contrast between scepticism and credulity, and converted it into a spectacular practice. The prosperity of this kind of shows was not only due to the appeal of deceptive practices but also due to the fact that against their sceptical spectators, the paying public, they were positing a credulous 'other': the spiritualist believer. Thus, the call for a scepticism-driven spectatorship has to be understood in relation to the possibility of being deceived that the craze for spiritualist seances implied. In the next paragraph, I will move to anti-spiritualist criticism developed in the psychological field, in order to show how spiritualist sitters were increasingly depicted as non-sceptical spectators in this context, too.

\section{Sensorial delusions: Spiritualism, psychology and spectatorship}


in 1874 , is one of the books collected by Harry Houdini and now conserved at the Library of Congress. In the first lines, the author defines the word 'phenomenon' as 'that which appears to be, but it is not what it appears' (1874: 1). The problem of perceptual delusion and its consequences are the subject of his study: 'We are deceived, there is no blinking the fact. We cannot look, listen, or move, without being deluded, appearing to see, hear, or move, what we neither see, hear, nor move' (p. 2). A sceptical perspective is pointed out as the prime solution of this problem. Scepticism 'does not deny the existence of reality; it insists that we cannot distinguish the reality from its appearance [...]. Scepticism does not negate reality, it only points triumphantly to its mocker, appearance-phenomenon' (p. 3). $</$ UIP $>$

As Jonathan Crary (1990), among others, has suggested, the physiological study of perception in the nineteenth century was haunted by the idea of illusion and sensory deception. Art historian Michael Leja has recently demonstrated how visual experience was becoming a matter of 'looking askance' in turn-of-the-century America: 'at one, the aspects of things in the world were recognized increasingly as deceptive; at the other, the human eye was revealing a dull tool, inadequate to its tasks. If seeing had ever been a basis for believing, it certainly was not now' (2004: 1). In the last decades of the century, some of the leading American practitioners of a young and still unstable science, psychology, developed a discourse on deception, scepticism and credulity that originated from a critical discussion of the spiritualist claims. Probably influenced by magicians' stage version of the spiritualist tricks, this discourse took often the shape of a debate on spectatorship and on the spectator's liability to delusion. Following this perspective, the medium was assimilated to the role of a performer, and seance-sitters to a kind of audience.

Among the writers of a 'psychology of spiritualism' was George Miller Beard, a U.S. neurologist still remembered for having coined the term neurasthenia in 1869. In 1879 he published an article in The North American Review, aiming at furnishing a psychological 
explanation for phenomena such as trance, mediumship and spirit communications. Pointing to "the unscientific state of the principle of evidence as derived from human testimony, that made spiritism a possibility and a power in these modern days', he categorically asserted that spirits 'only dwell in the cerebral cells' (1879: 67). Beard explained the belief of sitters in spiritual phenomena as a result of the emotional excitement that characterized the seance situation, to which he interestingly refers as 'suspense': 'suspense is the strongest of human emotions, and in an ordinary séance the emotions are kept in constant suspense' (68, emphasis in original). Under this condition, the brain may create objects accorded to what is repeated, desired or apprehended: 'the eye seeing what it looks for, the ear hearing what it wishes or fears' (p. 68). A psychologist, concluded Beard, had much to gain in observing the way people reacted to the alleged spiritual phenomena: 'spiritualism is, indeed, a precious mine of psychology, the veins of which grow wider and richer the longer we work them' (p. 77).

Another American neurologist, William Alexander Hammond, underlined the environmental condition that was customary in spiritual seances, and produced in the sitters false sensorial impressions or mind-created illusions:

In the dark, or in the uncertain light of the moon, or of artificial illumination, the liability to self-deception is very much increased; and if, in addition to the defect of light, there are continual sounds and other means of engaging the attention, it is exceedingly easy to induce sensorial confusion, and thus to impose upon the intellect. (1870: 235)

This description of the influence of darkness on the audience recalls similar issues regarding theatrical performances and, later, the cinematic spectacle. Among other factors increasing the opportunity of sensorial delusion, Hammond listed attention, that when concentrated upon 
any particular thing or part of the body might lead to erroneous perception, and the sleight of hand: 'the perfection to which this art is carried by accomplished performers is really remarkable, and is much more wonderful than would be real visitations of spirits' (p. 241).

The most interesting text that investigates spiritualism from a psychological perspective is probably Hugo Münsterberg's 'Psychology and Mysticism', published by the Atlantic Monthly in 1899. The German-born psychologist, who had moved to the United States in order to undertake the direction of Harvard's psychological laboratory, was probably the most important psychologist of the American academia at the turn of the century. Nevertheless, his scientific work is mostly forgotten today, perhaps also in consequence of his efforts to stop America's entry into World War I on behalf of the Allies (Carroll 1988: 489). However, his pioneering book on film theory, The Photoplay: A Psychological Study, was rediscovered in the 1970s by the psychoanalysis-oriented film scholarship and is today regarded as a classical work in film studies (Münsterberg 1970).

Münsterberg was concerned by the unstable state of psychology as a scientific discipline, which 'on account of the many changes in recent years, have so far not had the time to crystallize' (cited in Bruno 2009: 91). The alleged link between psychology and paranormal phenomena or psychical research was, for the Harvard professor, one of the obstacles that had to be overcome by American psychologists for acquiring the status that they deserved within the scientific world. Therefore, refusing conjectures that 'experimental Psychology treats of spiritualistic experiments' (cited in Bruno 2009: 97) was an urgent task to him. In 'Psychology and Mysticism', as well as in The Photoplay, Münsterberg attempted to apply psychology to issues of public interest, in order to stress the practical importance of this young science. The two texts share the same theoretical background, which pointed to the interdependency of mind and body. In an article published in an 1899 edition of Science with the title 'The Physiological Basis of Mental Life', the Harvard scientist had thus summarized 
his view: 'every sensation without exception is physiologically an innervation sensation, as it must have reached some degree of vividness to exist psychologically at all' (1899b: 446). His exposure of mysticism, defined as 'the belief in supernatural connection in the physical and psychical world' (1899a: 67), found an inherent justification in this framework. In fact, Münsterberg refused every depiction of psychological activities that were described as independent from physiological processes. Coherently, he grounded his refusal of psychic phenomena such as telepathy in the need for a physical mediation between the transmitter and the receiver: 'the psychologist insists that every perception of occurrences outside of one's own body and every influence beyond one's organism must be intermediated by an uninterrupted chain of physical processes' (p. 69). Also, spiritualism had to be rejected by the psychologist as 'the most repulsive claim of mysticism' (p. 84) because it rested upon a psychical influence accomplished without physiological intermediation.

Münsterberg's exposure of spiritualism did also include a link between seance-sitting and spectatorial experience. Discussing the reasons why he avoided spiritualist seances, the German-born psychologist compared them to a theatre-going:

It is not because I am afraid that they would shake my theoretical views and convince me of mysticism, but because I consider it undignified to visit such performances, as one attends a variety show, for amusement only, without attempting to explain them, and because I know that I should be the last man to see through the scheme and discover the trick. (p. 78)

It is interesting to note that his refusal of attending seances involved an acknowledgement of his own vulnerability to the medium's humbugs. In contrast with the majority of earlier antispiritualist writings, that accorded to the scientist a higher capacity of discerning truth from 
trickery, Münsterberg's text allowed the possibility for him to be deceived by the mediums: 'I should certainly have been deceived by Madame Blavatsky, the theosophist, and by Miss Palladino, the Medium. I am only a psychologist, not a detective' (p. 78). Apparently, although he claimed not to be afraid that a spiritualist seance 'would shake my theoretical views' (p. 78), his knowledge of the mechanisms of human perception did not seem enough for Münsterberg to protect his senses from being deceived. Some years later, however, Münsterberg decided to accept the challenge of those spiritualists that were asking him to attend a seance under 'test conditions', and was involved in one of the most celebrated exposés of the early twentieth century: the unmasking of the famous Italian medium Eusapia Palladino, whom Münsterberg caught while performing a trick (1969: 117-48). However, reporting the circumstances of this exposé, the Harvard professor did not forget to mention that any kind of person may be the subject of a medium's deception. In fact, he reasoned, the scientists are poor witnesses of these cases, since they are trained through their lives to breathe in an atmosphere of trust: 'if there were a professor of science who, working with his students, should have to be afraid of their making practical jokes or playing tricks on him, he would be entirely lost' (p. 121). In this way, Münsterberg helped to explain to contemporary readers how it was possible scientists such as William Crookes or the French astronomer Camille Flammarion had come to accept the spiritualist claim. It is interesting to note that this point also shares some similarity with Münsterberg's film theory. In fact, the idea that everyone might be perceptually tricked and deluded, to which he referred in both his antispiritualist essays, was also at the core of the mind-screen analogy in his work on cinema. This theory inaugurated a tradition of scholarship in film theory that remains influential even today. $</ \mathrm{UIP}>$

Psychologist Norman Triplett dedicated one year later, in 1900, a long essay to the 'psychology of conjuring deceptions', comparing the spectatorial strategy used on the stage 
by magicians with those of spiritualist mediums. Triplett, who was teaching at Clark University in Massachusetts at that time, argued that magic tricks profited of the audience's emotional state: "were the spectator in an ordinarily critical state he would know very well that blowing on a card is not an adequate cause for transforming it into another [...]. He is not at his best intellectually. The rational element is in abeyance' (1900: 497). A similar argument was used by Triplett in the discussion of a spiritualist seance:

It is difficult for the scientist to read himself into the peculiar state of mind of the 'sitters' who firmly believe that the spirit of their departed friends are really with them in the room, and who, by having their intelligence paralyzed by a belief in the supernatural, are easy marks for the charlatans who, despite frequent exposures, are continually springing up to take advantage of human frailty. Much of the effect is accounted for when the 'mise en scène' is held in remembrance: everything is so disposed as to contribute to an atmosphere of mystery. A darkened room; a circle of suggestible subjects infecting each other, and all strained to the highest pitch of vivid expectation: their psychical centers hyperaesthetically excited by the desire to learn of their loved ones whose images fill the mind, and whose actual presence is felt. These are not conditions conducive to sharp sight and logical judgement, but they make the work of the medium easy. In this abnormal state of the subjects the sensorial is almost at the mercy of the preperceptive element. Any rustling noise is attributed to spiritual agency; every light reflection is taken for a spirit form. (pp. 487-88)

Here, the depiction of the environment, the 'darkened room', as a possible cause for 
sensorial delusion, coexists with the relevance attributed to the 'particular state of mind' of the sitters, 'having their intelligence paralyzed by a belief in the supernatural'. The contrast between the credulity of these sitters and the readers of Triplett's writing, who should have been able to rationally distinguish between reality and trickery, recalls the magician's complicity with its audience in performing an anti-spiritualist exposé. Triplett's essay testifies the intention of providing not only a rational explanation but also the intellectual resources to distinguish between reality and illusion. His primary references were turn-of-the-century magic handbooks such as Hopkins' Magic: Stage Illusions and Scientific Diversions, Including Trick Photography (1897). The number and diffusion of these publications demonstrates that such books were meant to be not only a guide for amateur magicians but also a curiosity for readers interested in inquiring the reasons of their own sensorial deception. However, the fact that such tricks could be rationally explained and understood did not mean that the spectator could be immune to deception. The beginning of Triplett's essay, which explores the 'origins of conjuring' from the instinct of playing with perceptual deceptions in animals and children (440-47), clearly fixes the underlining reasoning of his work: anyone can be and is deceived. Coherently, the admission that everything happening on the stage might be a trick was an explicit acknowledgement of the vulnerability of our senses. Relying on magic literature for writing an essay on perceptual delusion, Triplett seems to share with other contemporary psychologists the attempt of demonstrating how 'we cannot look, listen, or move, without being deluded' (Andrews 1874: 2).

\section{Conclusion}

The analysis of anti-spiritualist criticism contributes to link the rise of a discourse on scepticism and visual competence in late-nineteenth-century America with the exposure of occultist theories and practices. In a historical period that was experiencing the spreading of 
increasingly complex advertising practices, drastic transformations in the urban environment and the introduction of visual technologies such as cinema, the faculty to maintain a non-naif perspective and to distinguish between reality and deception was being intensively called into question. As others have shown (Cook 2001; Leja 2004; Staiti 2002), a sceptical perspective was central to visual practices such as magic shows or trompe l'œil painting, which experienced an unprecedented success in America during these years. In connecting these developments with anti-spiritualist literature, this article shows that the positing of a nonsceptical counterpart, the spiritualist believer, was an inherent and relevant part of the process by which the fact that every spectator was subject to sensorial deception was taken into account.

A similar trajectory can be observed in other turn-of-the-century spectacular practices, and especially in early cinema. In particular, the consequences of a discourse that inquired spiritualism as a matter of scepticism and spectatorship can be better understood by recalling the 'train-effect' debate in film studies. One of the most common narratives that appears in connection with early cinema depicts the spectators as fearfully reacting to the moving images. Following this tradition, early audiences would have in some cases temporarily forgotten the fictional character of cinema: spectators would have screamed, or got up and run away from the hall. Because this narrative was usually connected with the image of an oncoming train, Russian film historian Yuri Tsivian successfully called it 'the train effect' (cited in Bottomore 1999: 177). Recent scholarship usually agree about the fact that such accounts have not to be taken literally. However, although they were at least in part apocryphal, they do suggest something about early cinema reception. In a widely cited essay, Tom Gunning has put this cinema's 'myth of origin' in connection with visual entertainments such as magic theatre, which challenged their spectators with a 'vacillation between belief and incredulity' (1989: 114-19). 
Much of late-nineteenth-century American fiction, the works of Mark Twain in particular, is inhabited by the figure of the uncultured bumpkin who takes theatrical production literally, and thus mistakes deception for reality. Lisa Gitelman referred to this as 'the narrative of the alien naif who mistakes mimetic representation for reality' (Gitelman 1999: 121). Such narratives were usually related to social, racial or sexual differences: countrymen, savages and other peripheral groups, which were put in contrast with a more informed and sceptical urban population. As many have noted (Bottomore 1999; Gunning 1989), one of the peculiarities of the early train-effect accounts is that the spectators who reportedly panicked before the screen were usually not described as urban audience, arguably the most relevant public for early cinema. Coherently with the 'narrative of the alien naif', countrymen, savages and madmen were reportedly the most common victims of cinema's excess of realism. Many texts that criticized the 'spiritualist madness' share a similar perspective, implying that a sceptical observer would not be tricked by mediums and accept the spiritualist claims.

However, the analysis of scholarship such as Münsterberg's 'Psychology and Mysticism' suggests that the depiction of ingenuous and non-sceptical viewers, the spiritualist believers, did not always cover the fact that everyone was vulnerable to sensorial delusion. Increasingly, American psychologists were acknowledging that scepticism and culture were not a sufficient protection against the fallacy of our senses. Even the psychologist had to admit the possibility of being deceived. It is probably not a coincidence that Münsterberg moved with apparent ease between film theory and the exposure of spiritualist phenomena. Although he would have visited a spiritualist seance or a movie theatre with the same unshakable scepticism, the German scientist knew that in both cases his senses were going to be deceived.

\section{Acknowledgements}


Natale 20

This article is the result of research prevalently undertaken at two archival institutions: the Library of the American Society for Psychical Research and the Harry Houdini Collection at the Library of Congress. A shorter version of this work was presented at the 2010 Southwest Texas Popular Culture/American Culture Association Conference, in the Skepticism and Culture Panel of the American Studies Area. 


\section{References}

Andrews, James (1874), The Psychology of Scepticism and Phenomenalism, Glasgow: James Maclehose.

A Medium (1891), Revelations of a Spirit Medium, or Spiritualistic Mysteries Exposed, St Paul: Farrington \& Co.

Bacon, George A. (1896), The Attitude of Scientific Men toward the Spiritual Phenomena, Boston: Banner of Light Publishing.

Barnum, Phineas Taylor (1865), The Humbugs of the World: An Account of Humbugs, Delusions, Impositions, Quackeries, Deceits and Deceivers Generally, in All Ages, New York: Carleton.

Barnouw, Eric (1981), The Magician and the Cinema, New York: Oxford University Press.

Beard, George M. (1879), 'The Psychology of Spiritism', The North American Review, 129: 272, pp. $65-80$.

Bottomore, Stephen (1999), 'The Panicking Audience?: Early Cinema and the "Train Effect", , Historical Journal of Film, Radio and Television, 19: 2, pp. 177-216.

Braude, Ann (1989), Radical Spirits: Spiritualism and Women's Rights in NineteenthCentury America, Boston: Beacon Press.

Bruno, Giuliana (2009), 'Film, Aesthetics, Science: Hugo Münsterberg's Laboratory of Moving Images', Grey Room, 36, pp. 89-113.

Carroll, Noël (1988), 'Film/Mind Analogies: The Case of Hugo Münsterberg', The Journal of Aesthetics and Art Criticism, 46: 4, pp. 489-99.

Cook, James W. (2001), The Arts of Deception: Playing with Fraud at the Age of Barnum, Cambridge, MA: Harvard University Press.

Crary, Jonathan (1990), Techniques of the Observer: On Vision and Modernity in the Nineteenth Century, Boston: MIT Press. 
Darby, M.E. (1888), An Investigation of Modern Spiritualism: An Exposé, South Shields:

M.E. Darby.

Davenport, Reuben Briggs (1888), The Death Blow to Spiritualism: Being the True Story of the Fox Sisters, as Revealed by Authority of Margaret Fox and Catherine Fox Jencken, New York: G.W. Dillingham.

During, Simon (2002), Modern Enchantments: The Cultural Power of Secular Magic, Cambridge, MA: Harvard University Press.

Gitelman, Lisa (1999), Scripts, Grooves, and Writing Machines: Representing Technology in the Edison Era, Stanford: Stanford University Press.

Gunning, Tom (1989), 'An Aesthetic of Astonishment: Early Film and the (In)Credulous Spectator', Art and Text, 34, pp. 31-45.

Gurney, E., Myers, F.W.H. and Podmore, F. (1962), Phantasms of the Living, New York: University Books (First published 1888).

Hammond, William A. (1870), ‘The Physics and Physiology of Spiritualism', The North American Review, 110: 227, pp. 233-60.

Home, Daniel Douglas (1877), Lights and Shadows of Spiritualism, London: Virtue \& Co.

Hopkins, Albert A. (1897), Magic: Stage Illusions and Scientific Diversions, Including Trick Photography, New York: Munn \& Co.

Houdini, Harry (1924), A Magician among the Spirits, New York: Harper \& Brothers.

Lamont, Peter (2004), 'Spiritualism and a Mid-Victorian Crisis of Evidence', The Historical Journal, 47: 4, pp. 897-920.

Leja, Michael (2004), Looking Askance. Skepticism and American Art from Eakins to Duchamp, Berkeley: University of California Press.

Maskelyne, John Nevil (1876), Modern Spiritualism: A Short Account of Its Rise and Progress, with Some Exposures of So-Called Spirit Media, London: F. Warne. 
McLean, Albert F., Jr. (1965), American Vaudeville as Ritual, Lexington: University of Kentucky Press.

Mnookin, Jennifer (1998), 'Image of Truth: Photographic Evidence and the Power of Analogy', Yale Journal of Law \& the Humanities, 10, pp. 1-74.

Moore, R. Laurence (1972), 'Spiritualism and Science: Reflections on the First Decade of Spirit Rappings', American Quarterly, 24: 4, pp. 474-500.

Münsterberg, Hugo (1899a), 'Psychology and Mysticism', Atlantic Monthly, 83: 495, pp. $67-85$.

__ (1899b), 'The Physiological Basis of Mental Life', Science, 9: 221, pp. 442-47.

— (1969), American Problems from the Point of View of a Psychologist, Freeport: Books for Libraries Press. First published 1910.

—_ (1970), The Film: A Psychological Study, New York: Dover Publications. First published 1913.

Newton, A.E. (1888), 'Why I Am a Spiritualist', The North American Review, 147: 385, pp. $654-68$.

Noakes, Richard J. (1999), 'Telegraphy Is an Occult Art: Cromwell Fleetwood Varley and the Diffusion of Electricity to the Other World', The British Journal for the History of Science, 32: 4, pp. 421-59.

Oppenheim, Janet (1985), The Other World: Spiritualism and Psychical Research in England, 1850-1914, Cambridge: Cambridge University Press.

Orvell, Miles (1989), The Real Thing: Imitation and Authenticity in American Culture, 1880-1940, Chapel Hill: University of North Carolina Press.

Owen, Alex (1990), The Darkened Room: Women, Power, and Spiritualism in Late Nineteenth Century England, London: Virago Press.

Page, Charles D. (1853), Psychomancy: Spirit-Rappings and Table-Tippings Exposed, New 
York: D. Appleton.

Peters, John Durham (1999), Speaking into the Air: A History of the Idea of Communication, Chicago: University of Chicago Press.

Salamanca, Lucy (1942), Fortress of Freedom: The Story of the Library of Congress, Philadelphia: Lippincott.

Sconce, Jeffrey (2000), Haunted Media. Electronic Presence from Telegraphy to Television, Durham: Duke University Press.

Solomon, Matthew (2006), 'Up-to-Date Magic: Theatrical Conjuring and the Trick Film', Theatre Journal, 58: 4, pp. 595-615.

Staiti, Paul (2002), 'Con Artists: Harnett, Haberle, and Their American Accomplices', in S. Ebert-Schifferer (ed.), Deceptions and Illusions: Five Centuries of Trompe L'Oeil Painting, Washington: National Gallery of Art, pp. 90-103.

Thurschwell, Pamela (2001), Literature, Technology and Magical Thinking, 1880-1920, Cambridge: Cambridge University Press.

Triplett, Norman (1900), ‘The Psychology of Conjuring Deceptions', The American Journal of Psychology, 11: 4, pp. 439-510.

Tucker, Jennifer (2005), Nature Exposed: Photography as Eyewitness in Victorian Science, Baltimore: Johns Hopkins University Press.

Weatherly, Lionel A. (1891), The Supernatural?, Bristol: Arrowsmith.

Winslow, Forbes L.S. (1877), Spiritualistic Madness, London: Baillière, Tindall, and Cox. 
Natale 25 


\section{Contributor details}

Simone Natale is Ph.D. candidate at the Graduate School in Communication Studies, University of Turin, Italy, with a project on spiritualism, entertainment and visual culture around 1900. He is currently Visiting Scholar at Concordia University, Montreal, Department of Communication Studies. His master's thesis on X-rays and visual media was awarded the Roberto Radicati Fellowship by the National Film Museum of Turin in 2006. He was DAAD Research Fellow at the University of Cologne, Germany, in 2005. He is researcher at the International Center of Studies Primo Levi, Turin, since its foundation in May 2008, and visiting researcher at the Mobile Media Lab in Montreal, Canada. Contact: Simone Natale, 2519 Rue Joliette, apt. 5, H1W 3H1 Montreal, Quebec, Canada.

E-mail: simone.natale@unito.it</UIP>

$<$ EN >1 For a most reliable and informed history of spiritualism in the United States, see Braude (1989). For more recent scholarship, see, among others, Peters (1999); Sconce (2000).

2 The most comprehensive history of the spiritualist movement in Great Britain is still Oppenheim (1985). See also Owen (1990); Thurschwell (2001).

3 On the role of recording devices in spiritualist seances, see Noakes (1999); Lamont (2004). The apparent ease with which spiritualism interacted with nineteenth-century positivism has moved historian Laurence Moore to argue that spiritualism was 'a religious faith which depended on seeing and touching' (1972: 484). $</ \mathrm{EN}>$ 